\title{
Danish under the influence of Spanish. In search of the Spanish se in Argentine Danish
}

\author{
ANNA SOFIE HARTLING
}

Today, Danish is spoken by a small minority of descendants of Danish emigrants to Argentina, and the language has been in contact with the surrounding majority language Spanish for more than 150 years. This contact has resulted in all sorts of transfer of linguistic material from Spanish to Danish. On the assumption that the structures being replicated and reanalyzed in the recipient language are, in particular, very frequent ones and inter-systemically equivalent ones, the article examines the influence of constructions involving the Spanish se particle in Argentine Danish. The article focuses on constructions influenced by se that contain sig (mig, dig, os, jer), especially where it is used reciprocally, but the study shows that all the functions of the Spanish $s e$ are represented by sig in Argentine Danish. In light of the analysis of se-influenced sig structures, which prove to be a field of great intra- and inter-speaker variation, the article discusses whether Argentine Danish can be considered a new independent variety of Danish.

KEYWORDS: Argentine Danish; contact linguistics; constructions with se; reciprocity; reflexivity 